\title{
PERCEPTION OF ROMANIAN CONSUMER ON QR CODE AS AN EXTENSION OF NUTRITION LABELLING
}

Article DOI: https://doi.org/10.35219/ann-ugal-math-phys-mec.2018.2.16

\author{
Adriana Elena Radu (Balaban) ${ }^{1, *}$, Petru Alexe $^{1}$, Stefan Pădure ${ }^{1}$, Adriana Macri², \\ Nastasia Belc ${ }^{2}$ \\ 1 "Dunarea de Jos" University of Galati, Faculty of Sciences and Environment, Romania, e-mail: \\ adriana.radu@ugal.ro \\ ${ }^{2}$ National Institute of Research and Development for Food Bioresources - IBA Bucharest, Ancuța Băneasa Street no 5, \\ Bucharest, România \\ *Corresponding author: adriana.radu@ugal.ro
}

\begin{abstract}
This paper is aimed to present the perception of consumers on the QR code as an extension of the nutrition food products label. This study was done on the Romania market in July - August 2018.

The methodology used was a quality and quantity market research. The quality research was done with the help of decision respondents from food industry (retailers and producers) from Bucharest and the Ilfov area. The quantity research was realized on a simple survey on 624 consumers from South-East, West of Romania, including Bucharest. They answered different questions in order to observe their perception on QR code. The questions were closed questions with multiple options of answers.

As a conclusion, $75 \%$ from our respondents are using a smart phone, which means that 7 from 10 respondents could access the information for food products using QR code from food labels. Romanian consumers seem to be interested in almost all information proposed to be added on QR code: on the first place is durability, followed by allergen information and on the $3^{\text {rd }}$ place is the nutrition declaration. From the nutrition declaration systems point of view our respondents ( 2 from 3 respondents) prefer to have implemented UK traffic light to the France Nutri Score.

The paper work was supported by the Core Program, project number PN 18020301.
\end{abstract}

Keywords: food products, label, nutrition food labelling, QR code, advertising.

\section{INTRODUCTION}

The Romanian consumers have seemed to be more informed lately, but food education is not structured in order to give them the possibility to make an objective selection of the food products. The education of Romanian consumers refers to good knowledge of the market offer and a good cooperation with it - our consumer seems to be more determined for what he wants and for what he is looking for, but in most cases the criteria are related to quality and price. The literature explains in details the increasing importance of improving human health condition through food and impact on consumer's choice on the environment. [1-5].

The aim of this paper is to identify the perception of the Romanian consumer on the QR code as an extension of nutrition labelling as mentioned in the abstract. The QR code added on the label of food products is seen as a tool for increasing the information level of consumers related to food products.

The QR code (quick response code) is a bar code which could be read by a smartphone or with a special reading device, which gives the consumer access to reading information from different links (storage location). In Romania food labelling is governed by local legislation, Romanian Governmental Decision no 106/2002 [6] and European legislation, Regulation (EU) No 1169/2011 of European Parliament [7]. 
Based on EU legislation, only mandatory information should be written in the local language, such as: name of product, list of ingredients, ingredients and processing aids which contain ingredients or substances causing food allergies, name of food business operator responsible for adding the product in EU market, net weight, the quantity of ingredients mentioned in the product's name or are emphasized on the label in words or pictures, nutrition declaration and others. Nutrition labelling has been mandatory since December 12, 2016.

It is known that Romanian local legislation is more restrictive than the EU legislation in terms of both pictorial requirements and information which should be added in the local language. According to the EU legislation, Regulation1169/2011, Article 15, which gives more flexibility to all EU markets only mandatory information which is defined in Article 9 must be written in the local language.. According to the Romanian legislation HG 106/2002 article 19, it is mandatory that all mentions written on the pack should be in the local language. Related to pictorial requirements, the Romanian HG 106/2002 allows us to use real, graphic or stylized picture only for the real ingredients which are mentioned on the product label. The icon (real, graphic or stylized picture) must be followed by the percentage of that ingredient. No minimum percent is required for real ingredients. When using natural flavouring or flavouring it is forbidden to use any type of graphic representation. According to local and EU legislation, health and nutritional claims are not mandatory to be written on the label. If still these claims are mentioned on the label they must be in compliance with Regulation (EC) 1924/2006 [8]. As seen in the literature, the label of food products is a channel delivering information from producer to consumer. $[9,10]$.

This paper shows that Romanian consumers are interested in almost all information proposed to be added in the QR code. 75\% of the total number of respondents who are using a smart phone and could easily access the information, are intent on using it.

The information considered more important to be added on the QR code is: the date of minimum durability of the product, allergen information, nutrition declaration, list of ingredients. Standard reference and EU importer details are irrelevant to Romanian consumers.

\section{MATERIALS AND METHODS}

The paper, including the market research was supported by the Core Program, project number PN 18 020301 and it was done using the input provided by a specialized market research company. All data were been collected with the help of survey run with Gizmo survey soft and analysed with IBM SPSS Statistical program.

2.1 The quality research - was done using in-depth interviews with 6 stakeholders from the food industry: 3 interviews with decision-making persons from the Commercial area (Bucharest and Ilfov) and another 3 interviews with decision-making persons from the Production area (Bucharest and Ilfov).

2.2 The quantity research - was completed using the TAPI (Tablet Assisted Personal interviewing) method, which means the interviews were done face to face with the respondents (consumers).

The interviews for the quality and quantity research were done based on a 19 items questionnaire, related to the information proposed to be added to the QR code.

The structure of the respondents' sample is representative at national level (based on Romanian census from 2011) and it consists of a group of 624 consumers above 18 years of age, from both the rural and urban areas. This market research had an error margin of $+/-4 \%$ and a confidence interval of $95 \%$.

\section{RESULTS AND DISCUSSION}

\subsection{Quality research.}

\subsubsection{Romanian consumer and food education.}

Nowadays, the Romanian consumer is more informed, he has an easy access to food information on the internet, in most of the cases, and he can find different information about food additives, ingredients and their benefits. During the promotion periods, the respondents from urban area are using the internet daily, in order to find more information about promotions and food products.

The QR code is a tool which is very well known by the Romanian producers and they use it to give more information about products and promotions. Briefly, the QR code invites the consumer to research beyond the label. 
In 2015, ScanLife declared that the most information accessed via the QR code was the information related to different products, eCommerce, video, application downloads and coupons [11]. Moreover, the QR code is a method of providing different information related to food products: it could not be added on the label because of limited space of the pack dimension or it could be repeated in order to increase the level of consumer information related to the food product for a better food choice.

The benefits of using the QR code are: it involves a small area on the label, the consumer could access different links with unlimited information related to food products, and/or promotional campaigns and the information is updated in real time. The disadvantages of using the QR code: it apparently addresses young consumers who access the information very easily online, using different applications which must be installed on smart mobiles. The application can consume from the storage space.

3.1.2 Perception of Romanian producers and retailers on QR code.

The study shows that the respondents are willing to use the QR code on the label, if it spreads on a small area, already overcrowded by legislation requirements.

Our respondents are interested in adding on QR code the information related to food products which could not be added on the label because of the limited space: a story, different movies, the technological process, instructions of preparation, promotion details. In the first part of interview the respondents were not interested in repeating the information from the label on the QR code. The proposed information to be added on QR code was accepted as an additional information.

The information suggested to be added on the QR code is the following: legal name, country of origin or place of provenience for product or primary ingredient, name of food operator (producer), name of the importer on EU market, the list of ingredients, ingredients or processing aids which may cause intolerances or allergies, net weight, the quantity of certain ingredients which are written in the product name, the date of minimum durability, storage conditions, the use instructions when the lack of performance hinders the correct use of the food product, the reference standard for production of food product (company standard Romanian standard, international standard), the nutrition declaration per $100 \mathrm{~g} / 100 \mathrm{ml}$, the nutrition declaration per portion size, the value of energy and quantity of nutrients reported to reference intake, the percentage of alcohol for food products with the percentage of $\%$ of alcohol more than $1.2 \%$.

The retailer`s and producer`s respondents were highly interested in the following information to be added on the QR code and they are intent on using it: the list of ingredients (with food additives number, the name of food additive, the quantity and benefits of ingredients), the durability of food products, ingredients or processing aids which are causing intolerances or allergies, the quantity of ingredients which are written in the product name, storage conditions, the use instructions, nutrition declaration per $100 \mathrm{~g} / 100 \mathrm{ml}$, nutrition declaration per portion size or consuming unit, value of energy and quantity of nutrients related to reference intake.

The respondents from the production and retailer representatives underline that there is a high interest on the part of the Romanian consumers in the list of ingredients, ingredients or substances which are causing allergies, the quantity of ingredients which are on the label and in nutrition declaration per $100 \mathrm{~g}$, portion size or consuming unit.

Different studies mentioned that the nutrition declaration on food products label may be considered a cost-effective method in communicating nutrition information to the final consumer, because this information is on the pack in the point of sale [12]. Food labels could be considered a moderator of relation between dietary behaviors and nutrition knowledge $[13,14]$.

\subsection{Quantity research.}

3.2.1 The demographic characteristics of the samples. The main demographic characteristics of the study respondents are described bellow in Figures $1-3$ and Table 1.

A total of $57 \%$ respondents reported to be highly informed, having high school degree. The study shows that this category of consumers are more interested in participating at different market research, maybe because they are interested in their lifestyle. Literature reports that the Romanian people with a university degree are preoccupied by healthy food [15]. 
Table 1. Demographic criteria per region.

\begin{tabular}{|l|c|c|c|l|}
\hline \multicolumn{1}{|c|}{ Regions (\%) } & $\begin{array}{l}\text { Small urban (<20 } \\
\text { k population) }\end{array}$ & $\begin{array}{l}\text { Medium urban (20- } \\
\text { 100k population) }\end{array}$ & $\begin{array}{l}\text { High urban (>100 k } \\
\text { population) }\end{array}$ & Rural \\
\hline $\begin{array}{l}\text { South (Muntenia + } \\
\text { Oltenia) }\end{array}$ & $3 \%$ & $5 \%$ & $5 \%$ & $19 \%$ \\
\hline $\begin{array}{l}\text { East (Moldova + } \\
\text { Dobrogea) }\end{array}$ & $2 \%$ & $4 \%$ & $5 \%$ & $14 \%$ \\
\hline $\begin{array}{l}\text { West (Transilvania + } \\
\text { Banat) }\end{array}$ & $4 \%$ & $5 \%$ & $5 \%$ & $16 \%$ \\
\hline Bucharest & & & $5 \%$ & \\
\hline
\end{tabular}

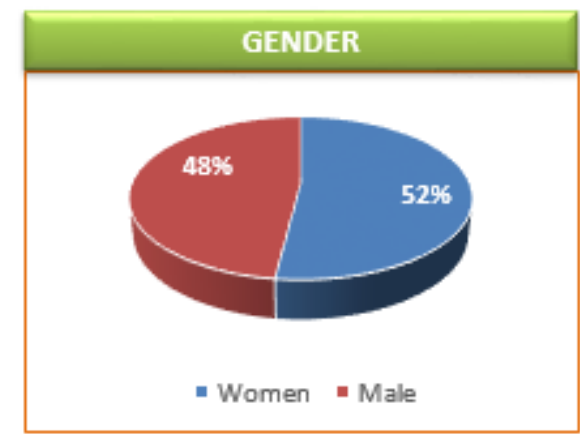

Figure 1. Demographic criteria - gender

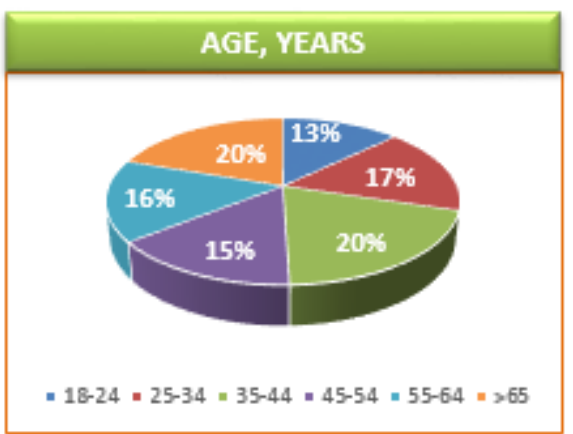

Figure 2. Demographic criteria -age, years

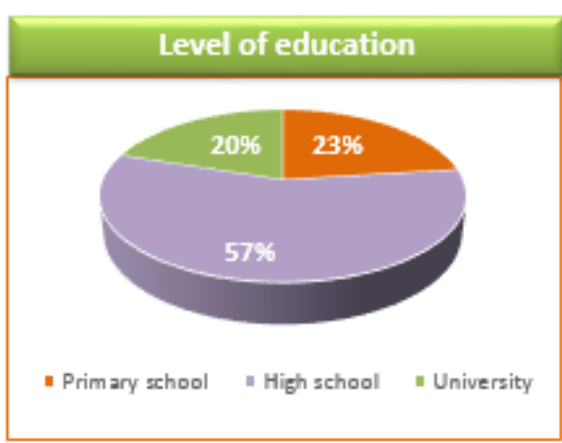

Figure 3. Demographic criteria - level of education

3.2.2 Importance of the information proposed to be added on the QR code of food products from the consumers' point of view.

The respondents were asked to identify the importance of each information presented to be added on the QR code on a scale between 1 to 5 , where 1 means not important, 2 - less important, 3 - neither important nor unimportant, 4- important and 5 -very important.

In Figure 4, we could observe their preference choice based on their age regarding the importance of information proposed to be added in the QR code. 


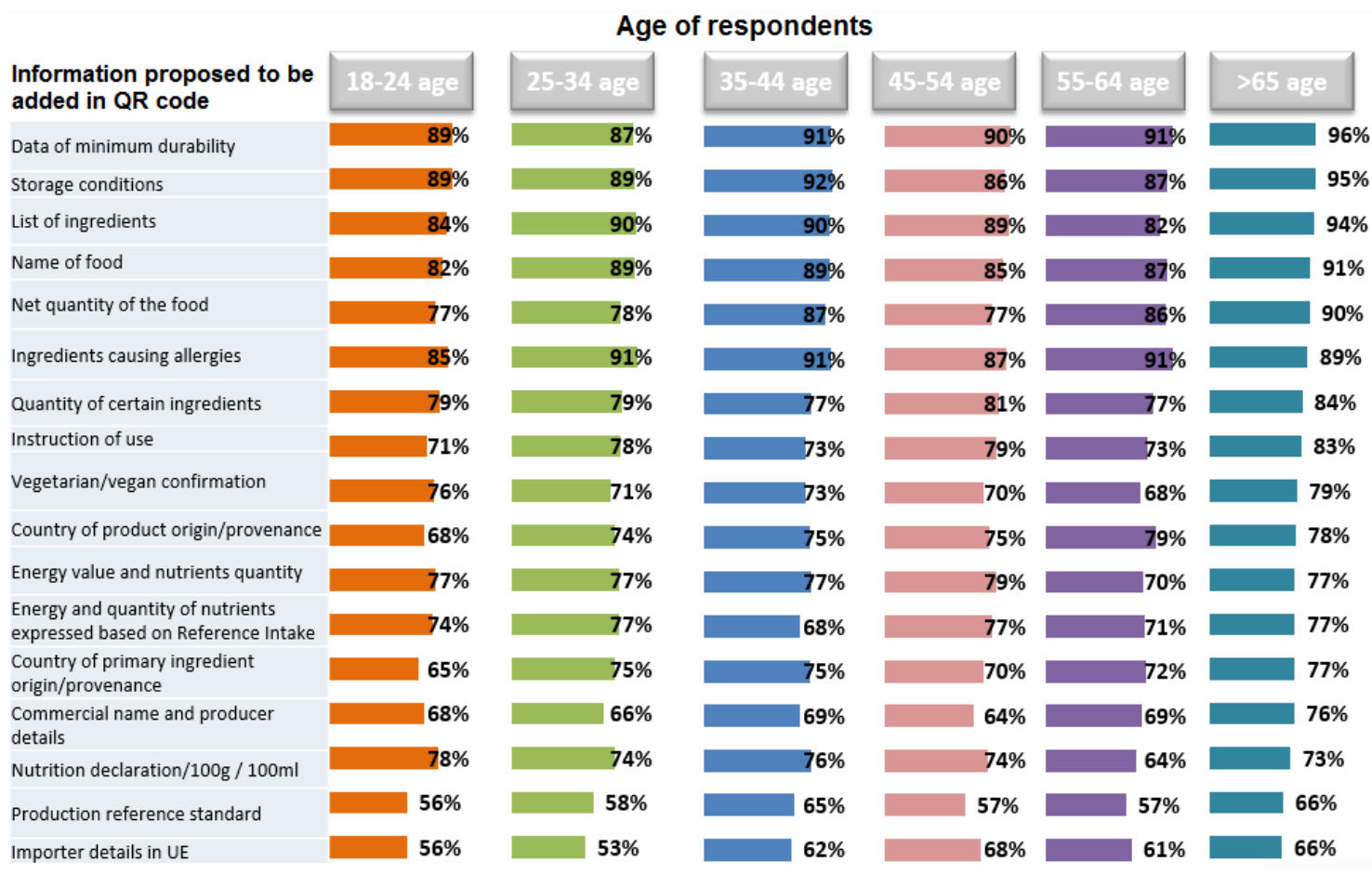

Figure 4. Importance of food information proposed to be added in QR code on food label, from each consumer's age category point of view.

The results show - that respondents with age between 18 and 54 years manifest a high interest in the introduction into the QR code of the following information related to food products: the date of minimum durability, storage condition, list of ingredients, name of food, net quantity of food, ingredients causing allergies/intolerance, quantity of certain ingredients, instructions for use, confirmation if the product is for vegetarians or vegans, country of origin or provenance, the nutrition declaration per $100 \mathrm{~g} / 100 \mathrm{~g}$, energy value and nutrients quantity per portion or consumption unit and the energy value and quantities of nutrients to be expressed as a percentage of the reference intake.

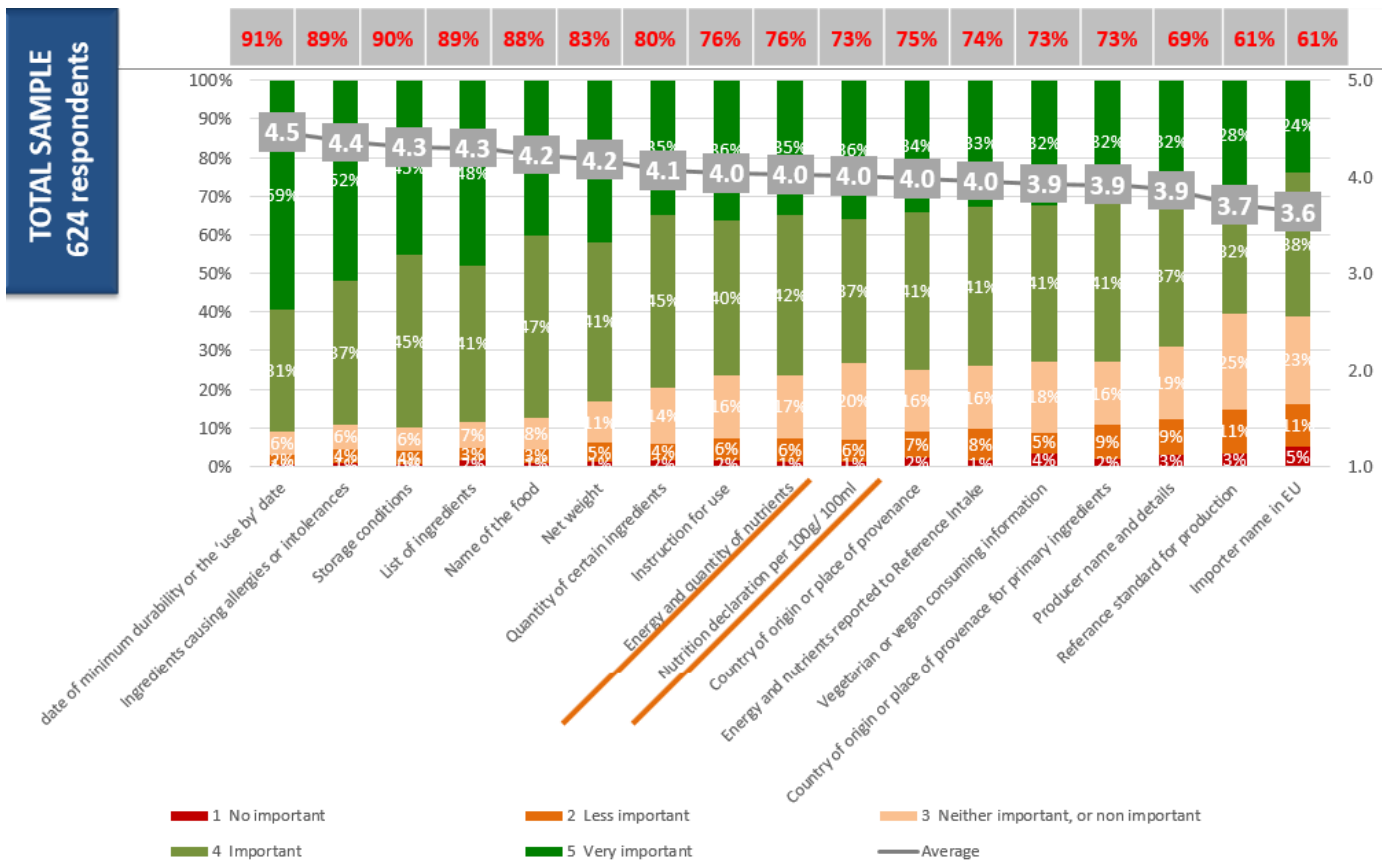

Figure 5. Importance of food information proposed to be added in QR code on food label from Romanian respondents' point of view.

Figure 5, shows their preference choice for the information proposed to be added in the QR code. From 17 pieces of information proposed to be added in the QR code, our respondents considered that 12 
pieces are important and very important for consumers and they voted with a score between 4 and 5 points. The result underlines again that the information "date of minimum durability or "use by" and "ingredients which are causing allergies or intolerance" are considered by consumers very important and important and are they voted with an average score $4.5-4.4$ from 5, followed by "list of ingredients and storage condition" with a score 4.3 from 5. Our consumers also considered to be important the information "nutrition declaration per $100 \mathrm{~g} / 100 \mathrm{ml}$ " and "quantity of nutrients and their values reported to reference intake of an average adult $(8400 \mathrm{~kJ} / 2000 \mathrm{kcal})$ ", which receive a score 4 from 5 .

The last of favorite information to be added on the QR code from our respondents' point of view is the information related to "the name of the importer on EU market" and "reference standard of food production" which received a score 3.6 - 3.7; this means that from their point of view, this information has an average importance.

Frequently consumers consult the list of ingredients, they are mainly looking at food additives. Different studies reported also that consumers consults list of ingredients, including (including also the claims and nutrition declaration on the pack), 52\% in one study [16] and 78\% in another study [17].

2.2.3. The front of pack nutrition labelling. During the interviews, 2 pictures for the front of pack nutrition labelling were presented to our respondents, i.e. 1 picture with Traffic light, the system from the UK (Figure 6) [18] and another picture with Nutri score system, used in France (Figure 7), where the level/quantity of each nutrient is marked by a color based on their nutrient profile and they were asked to identify the system they preferred to be added in QR code on the label.

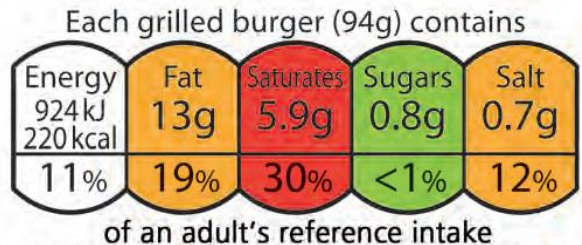

Typical values (as sold) per 100g: Energy $966 \mathrm{~kJ} / 230 \mathrm{kcal}$

Figure 6. Example of traffic light labelling used in UK. [18]

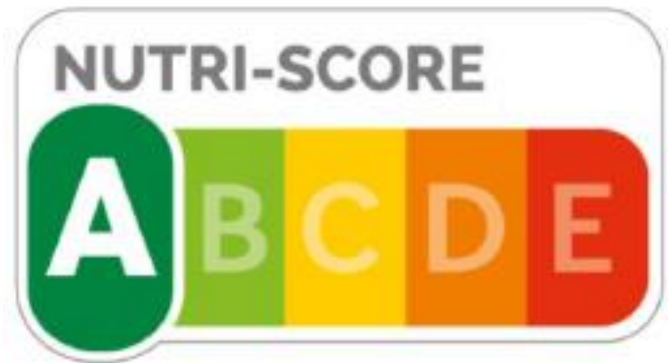

Figure 7. Example of Nutri score used in France. [19]

The results show - that $65 \%$ of our respondents prefer the UK Traffic light on our label, followed by $35 \%$ who prefer the Nutri score system.

The respondents were asked to identify the importance to be added on the QR code the front of pack nutrition labelling system used in the UK or Nutri score used in France, on a scale between 1 to 5 , where 1 means no important, 2 - less important, 3 - neither important nor unimportant, 4 important and 5 very important. The result shows that the UK Traffic light system was considered important by $81 \%$ of the respondents to be added on the label in the QR code.

Figure 8 below shows their preference choice regarding the importance of the front of pack nutrition labelling to be added on the QR code. The result shows that the UK Traffic light system is considered important and very important to be added on the label on the QR code by $81 \%$ respondents. 


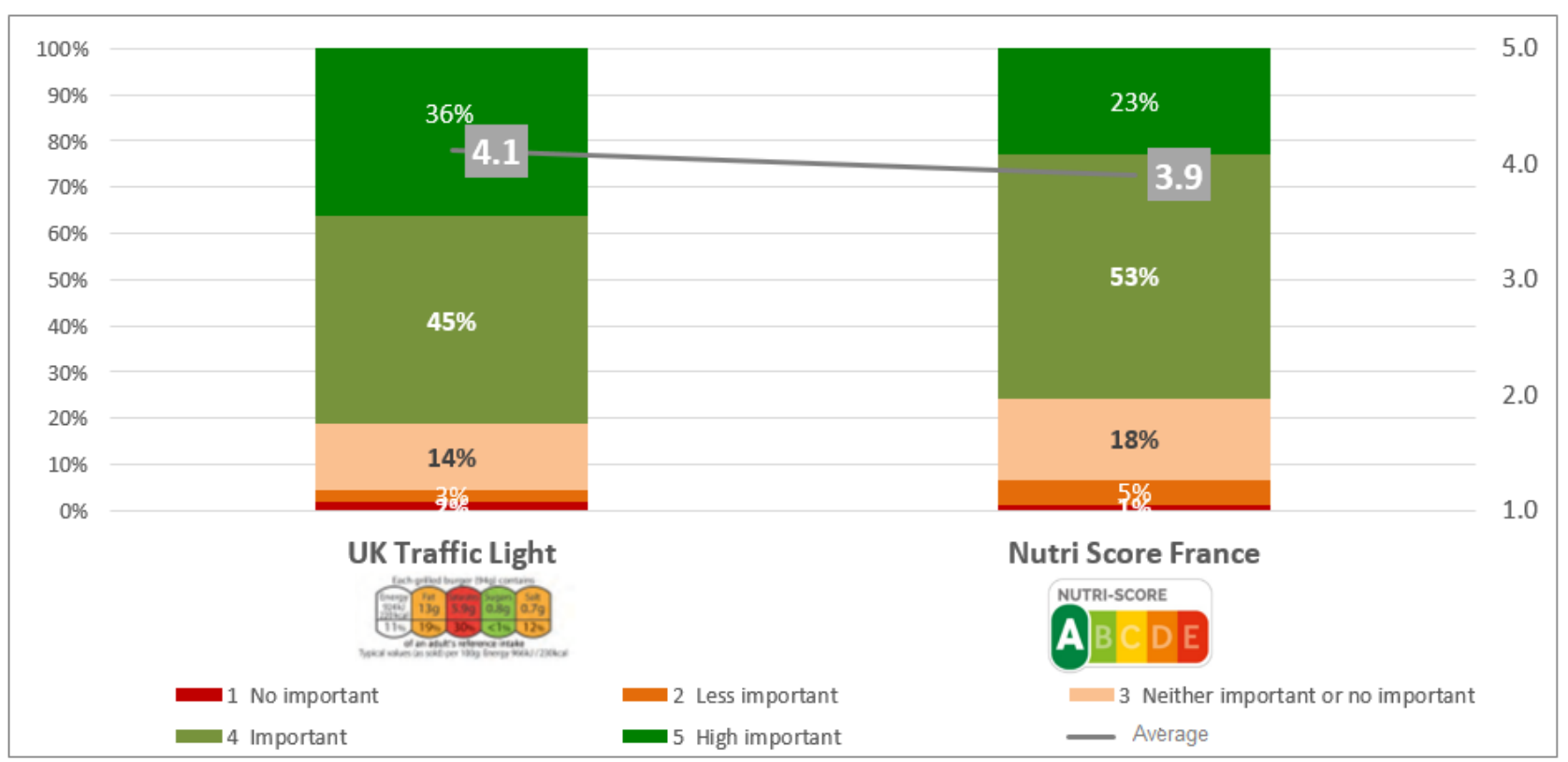

Figure 8. Importance of front of pack nutrition labelling added the QR code.

In the USA there is also a variety of front of pack nutrition labelling system [20], initiated by industry and different studies are run to find the consumer's perception. In one study run by FDA, it is stated that $67 \%$ of the respondents are using the front of pack nutritional system often or sometimes, when they are doing the purchasing decision [21] and because these systems are not standardized, it is very difficult for consumers to evaluate and to compare the nutrient profile of food.

\section{CONCLUSIONS}

The findings of this study suggest that it is important to add the QR code on the food package with the aim to increase the consumer's knowledge related to benefits products. Romanian consumers are very interested in all the information proposed to be added on QR code, in particular the big interest is underlined for the information related to the durability of food products, the substance and ingredients which are causing intolerance or allergies and the list of ingredients. The nutrition declaration is very well appreciated by women, maybe because in the culture of Romanian consumers, women take care of the family, especially meals and the education of children. Based on the specialist literature, the front of pack nutrition labelling is the key for a better choice of food product in the moment of purchasing.

Although the review highlights that Romania's consumers are interested in having the QR code added on the food products label in order to have access to more information related to food products (promotion, advertising, nutritional benefits, story of food product, different options to consume the product) and also to develop their culture from the point of view of the nutritional benefits of food products.

\section{References}

1. Jolly, D., Schutz, H., Diez-Knauf, K., \& Johal, J. (1989). Organic foods: consumer attitudes and use. Food Technology, 43 (11), 61-66.

2. Grankvist, G., \& Biel, A. (2001). The importance of beliefs and purchase criteria in the choice of eco-labelled food products. Journal of Environmental Psychology, 21, 405-410.

3. Magnusson, M. K., Arvola, A., Koivisto Hursti, U. K., Aberg, L., \& Sjoden, P. O. (2001). Attitudes towards organic foods among Swedish consumers. British Food Journal, 103, 209-226. 
4. Lee, W. C. J., Shimizu, M., Kniffin, K. M., \& Wansink, B. (2013). You taste what you see: Do organic labels bias taste perceptions? Food Quality and Preference, 29, 33-39.

5. Klont R. 1999, Growing organic food. World Ingredients (May/June), 40-44. Mondelaers, K., Aertsens, J., \& Huylenbroeck, G. V. (2009). A meta-analysis of the differences in environmental impacts between organic and conventional farming. British Food Journal, 111, 1098-1119.

6. Governmental Decision no. 106/2002 on food labelling amended by the following acts: HG 1822/2005; HG 173/2006; HG 1357/2006; HG 1529/2007; HG 751/2008; HG 685/2009; HG 796/2011;

7. Regulation (EU) no 1169/2011 of the European Parliament and of the council of 25 October 2011 on the provision of food information to consumers, amending Regulations (EC) No 1924/2006 and (EC) No 1925/2006 of the European Parliament and of the Council, and repealing Commission Directive 87/250/EEC, Council Directive 90/496/EEC, Commission Directive 1999/10/EC, Directive 2000/13/EC of the European Parliament and of the Council, Commission Directives 2002/67/EC and 2008/5/EC and Commission Regulation (EC) No 608/2004 amended by Commission Delegated Regulation (EU) No 1155/2013 and Commission Delegated Regulation (EU) No 78/2014.

8. REGULATION (EC) No 1924/2006 OF THE EUROPEAN PARLIAMENT AND OF THE COUNCIL of 20 December 2006 on nutrition and health claims made on foods

9. Bernues, A., Olaizola, A., \& Corcoran, K. (2003). Labelling information demanded by European consumers and relationships with purchasing motives, quality and safety of meat. Meat Science, $65,1095 \mathrm{e} 1106$.

10.Grunert, K. G., Wills, J. M., \& Fernandez-Celemin, L. (2010). Nutrition knowledge, and use and understanding of nutrition information on food labels among consumers in the UK. Appetite, 55, $177 \mathrm{e} 189$.

11.ScanLife, "Mobile Trend Report Q1 2015," 2015. http://www.scanlife.com/assets/images/pdf/ScanLife_2015_Q1_Trend_Report.pdf.

12.Campos, S., Doxey, J., \& Hammond, D. (2011). Nutrition labels on pre-packaged foods. A systematic review. Public Health Nutrition, 14(08), 1496-1506. doi:10.1017/S1368980010003290.

13.Fitzgerald, N., Damio, G., Segura-Pérez, S., \& Pérez-Escamilla, R. (2008). Nutrition knowledge, food label use, and food intake patterns among Latinas with and without type 2 diabetes. Journal of the American Dietetic Association, 108(6), 960-967. doi:10.1016/j.jada.2008.03.016.

14.Satia, J. A., Galanko, J. A., \& Neuhouser, M. L. (2005). Food nutrition label use is associated with demographic, behavioral, and psychosocial factors and dietary intake among African Americans in North Carolina. Journal of the American Dietetic Association, 105(3), 392-402.

15.Zugravu et al. / AUDJG - Food Technology (2017), 41(1), 50-61. Attitudes towards food additives: a pilot study Corina Aurelia Zugravu, Elena Narcisa Pogurschi, Daniela Patrascu, Petronela-Diana Iacob1, Carmen G. Nicolae.

16.Ollberding, N. J., Wolf, R. L., \& Contento, I. (2010). Food label use and its relation to dietary intake among US adults. Journal of the American Dietetic Association, 110(8), 1233-1237. doi:10.1016/j.jada.2010.05.007.

17.Norazmir, M. N., Norazlanshah, H., Naqieyah, N., \& Anuar, M. I. K. (2012). Understanding and use of food package nutrition label among educated young adults. Pakistan Journal of Nutrition, 11(10), 934-940. doi:10.3923/pjn.2012.934.940.

18. Guide to creating a front of pack $(\mathrm{FoP})$ nutrition label for pre-packed products sold through retail outlets, 2003, UK.

19.Décrets, arrêtés, circulaires textes généraux ministère des solidarités et de la Santé Arrêté du 31 octobre 2017 fixant la forme de présentation complémentaire à la déclaration nutritionnelle recommandée par l'Etat en application des articles L. 3232-8 et R. 3232-7 du code de la santé publique NOR : SSAP1730474A.

20.Center for Science in the Public Interest (2010) Food labeling chaos: the case for reform. http://cspinet.org/new/pdf/food_labeling_chaos_report.pdf (accessed October 2010).

21.Choinie're CJ, Lando AM (2010) 2008 Health and Diet Survey. http://www.fda.gov/Food/ScienceResearch/ResearchAreas/ConsumerResearch/ucm193895. 